He expressed this as an artificial epigenesis and differentiation and found it to be surprisingly similar to that in living organisms. Bailey refers to this work and its current solution (which is based on the low probability of information transmission in the gene model) but fails to see that this is not some fancy intermath'. It is circuit design of a classical kind that can be understood by first-year engineering students armed with a bit of boring old probability theory.

One should also bear in mind that emergence is well-trodden ground. The computer-design pioneer and multimath John Von Neumann worked with cellular automata with emergent properties (such as self-replication) in the early 1950 . And the mathematician John Conway published his celebrated "game of life" before 1970 . The game also relies on the emergent properties of a two-dimensional network of nodes with simple rules, as Bailey fully acknowledges. The point is that emergence has been accepted and studied as an interesting phenomenon and has not in fact been rejected because of an occasional lack of mathematical tractability, which is what Bailey implies.

Another theme in the book is that only now have computers become parallel enough for emergence to be properly applied. But even the Connection Machine, which Bailey sees as an example of an engine that will lead to the new era, has been around for more than ten years, and not much of an 'intermath' revolution is in evidence - just some interesting applications that are mentioned in the book. Of course, the author feels that evangelists such as himself are needed to bring the revolution about, the message being the seeming heresy of letting the computer get on with it without attempting to impose the limitations of human thought on its programs.

Putting the excesses of this view aside, the book has compelling and interesting qualities. It is written as an inventive structure dividing scientific history into concern with 'place and geometry' in antiquity, 'pace and industry' from the Middle Ages on, and 'pattern' as the mark of science that should guide us towards the next millennium. But perhaps its strongest commendable quality is that it might attract readers of popular science, particularly younger ones, to the fascinating topic of emergent and adaptive computation. This may provide a more adventurous reason for becoming a computer scientist or engineer than the prospect of making systems for endless browsing on the Internet.

Igor Aleksander is in the Department of Electrical and Electronic Engineering, Imperial College, Exhibition Road, London SW7 2BT, UK.

\section{How much is an elephant worth?}

Thomas E. Lovejoy

The Value of Life: Biological Diversity and Human Society. By Stephen R. Kellert. Island/Shearwater: 1996. Pp. 263. $\$ 24.95$.

The Sixth Extinction. By Richard Leakey and Roger Lewin. Doubleday/Weidenfeld and Nicolson: 1995. Pp. 271. \$24.95, £18.99.

Conservation and Biodiversity. By Andrew P. Dobson. W. H. Freeman/Scientific American Library: 1996. Pp. 264. $\$ 32.95, £ 19.95$.

THE major biological transformation of the planet that is already well under way can be viewed from a variety of perspectives. Conservation and Biodiversity is essentially a biologist's analysis of the challenges and solutions. The Sixth Extinction sets the biodiversity crisis in the context of the history of life. And The Value of Life examines human attitudes as the ultimate causes of the problem and means of redress.

In The Value of Life, Stephen Kellert contemplates the various values humans accord to other living things. There is much here that is new scholarship, at least in book form, and in that sense the volume is far the richest of the three for the conservation professional. The author identifies nine basic values, from utilitarian to moralistic. He also adds a tenth, theistic, in a brief consideration of the Kalahari Bushmen. Missing (in my view) is the 'library' value, the inestimable amount we can learn from studying the products of evolution, and which can strengthen the utilitarian argument.

The Value of Life is immensely stimulating, tending to inspire new questions with every one it answers. The excellent graphics help a great deal in the interpretation. Most of the work focuses on the attitudes of Americans. Some of the findings are not that surprising, for example that urban dwellers - in a biodiversity echo of Rousseau - tend to relate more romantically to wildlife than rural dwellers, especially when it comes to questions about, say, wolf reintroduction. In a survey of people's attitudes to groups of organisms, birds come out top, invertebrates bottom. Whales have emerged over the past couple of decades with a special status owing to our increased awareness of their intelligence and songs. This effect is not yet pronounced in Norway and Japan, where harvest of these mammals is still very much part of the national culture. Education has a strong effect on humanistic and moralistic values, but the decline in the latter among older Americans could be as much generational as a real reflection of ageing.
The comparison of the United States, Japan, Germany and Botswana is intriguing, with Japan having a much stronger controlling attitude to nature. The saddest note in the book is the decay among Bushmen of feelings of intimacy and kinship with nature, caused by cash incentives for harvest. Analysis of specific situations shows that attitudes vary greatly depending on the kind of animal and its natural history. The last two chapters usefully consider how knowledge of this sort should inform wildlife management, bureaucracies and education.

Conservation and Biodiversity displays the high-quality text and illustrations that one has come to expect of books in the Scientific American Library series, although, amazingly, Evelyn Hutchinson's, Stuart Pimm's and Timothy Wirth's surnames, and Costa Rica's INBio (National Institute for Biodiversity), are misspelled. The coverage is comprehensive, ranging from the ample chapter on "What is Biodiversity?" through to causes of extinction, including extensive sections on habitat fragmentation and loss, and ex situ and in situ conservation. "Biodiversity in a Changing World" gives excellent coverage from human demographics to climate change, and "The Wealth of Nature" deals with topics as diverse as bio-prospecting and ecotourism. Although direct citations do not appear in the text, the book contains a useful bibliography, making it eminently suitable for a course on the subject.

The Sixth Extinction, another superb work from the partnership of Richard Leakey and Roger Lewin, provides a wellillustrated tour of the history of life on Earth and describes Leakey's own personal odyssey, from his study of early hominids to his becoming a concerned conservation protagonist. It is a compelling introduction, grounded in the best modern science (from chaos theory to hominid evolution), to the reasons why the sixth extinction is generically different from previous mass extinctions - and certainly not in humanity's interest. Regrettably, there is no mention of the implications of human-induced climate change, but this does not detract from the book's value to the lay person.

The authors' treatments of the African elephant population and its management exemplify the different approaches of the three books. Dobson considers the issue in terms of the most effective culling strategy, whereas Kellert looks at it in terms of the value-sets of the pro- and anti-culling forces. Leakey, on the other hand, makes a compelling case that elephants, like whales, are special animals, so ethics should rule out any use. One must conclude that any interested person should seek a variety of perspectives.

Thomas E. Lovejoy is at the Smithsonian Institution, 1,000 Jefferson Drive, SW, Suite 320, Washington DC 20560, USA. 